\title{
Nitrogen Dissociation Rate at Solid Surface of Ferrous Alloys
}

\author{
Hideki ONO-NAKAZATO, Akitoshi MATSUI and Tateo USUI \\ Department of Materials Science and Processing, Graduate School of Engineering, Osaka University, 2-1 Yamadaoka, Suita, \\ Osaka 565-0871 Japan.
}

(Received on October 4, 2001; accepted in final form on November 22, 2001)

\begin{abstract}
The nitrogen dissociation rates at the surface of solid iron-M (M: Si, Al, Mn, Cr, and Ti) alloys have been measured by an isotope exchange technique at temperatures ranging from 1473 to $1798 \mathrm{~K}$. From the present results, the rate constant of nitrogen dissociation at the surface of pure solid iron is derived as $1.97 \times 10^{-5}\left[\mathrm{~mol} /\left(\mathrm{cm}^{2} \cdot \mathrm{s} \cdot \mathrm{atm}\right)\right]$ at $1773 \mathrm{~K}$ and the apparent activation energies for the nitrogen dissociation at the surfaces of $\delta$-Fe and $\gamma$-Fe ([mass ppm O] $=10.3$, [mass ppm S] $=7$ ) at $P_{\mathrm{N}_{2}}=0.05(\mathrm{~atm})$ are calculated as 127 and $162(\mathrm{~kJ} / \mathrm{mol})$, respectively. The effects of the alloying elements on the nitrogen dissociation rate at the surface of solid iron have the same tendency as those at the surface of liquid iron investigated previously by a similar method to the present study; the nitrogen dissociation rate is increased by the addition of $\mathrm{Mn}, \mathrm{Cr}$, or $\mathrm{Ti}$ and is decreased by the addition of $\mathrm{Si}$ or Al. The degree of the effects of increasing or decreasing the rate by the alloying elements for the solid iron is found to be smaller than that for the liquid iron.
\end{abstract}

KEY WORDS: nitrogen dissociation; isotope exchange; activation energy; solid iron; rate constant; chemical reaction; alloying element.

\section{Introduction}

Nitrogen dissolves into molten iron during its refining processes and even a small amount of nitrogen in steel causes harmful effects on the mechanical properties. Accordingly, it is important to evaluate the nitrogen dissolution rate in molten iron and many kinetic studies have been carried out. ${ }^{1-11)}$ Byrne and Belton ${ }^{3)}$ firstly measured the nitrogen dissolution rate by an isotope exchange technique and showed the effect of carbon is negligibly small up to the addition of 4.3 mass \%. Glaws and Fruehan ${ }^{4)}$ measured the nitrogen dissolution rate by both sieverts and isotope exchange techniques and compared those results. The dissociation of nitrogen molecule at the surface of molten iron was proven to be a rate-limiting step. Ban-ya et al. ${ }^{\text {) }}$ measured the nitrogen removal rate from molten iron, the effects of $\mathrm{C}$ and $\mathrm{Cr}$ upon which were investigated. Kobayashi et al. ${ }^{7}$ measured the nitrogen dissolution rate by the isotope exchange technique and showed the reaction is a first order with respect to the nitrogen partial pressure and the activation energy is calculated $95 \mathrm{~kJ} / \mathrm{mol}$. By one of the present authors and others, ${ }^{8)}$ the effects of $\mathrm{Ti}, \mathrm{Zr}, \mathrm{V}$, and $\mathrm{Cr}$ on the rate were previously investigated by the same technique. It is shown that the elements which have stronger affinity with nitrogen than iron increase the rate and the reason is explained by an increase of the activity of the vacant site at the metal surface. A correlation between the effects of increasing the rate and the interaction parameters of the additive elements with nitrogen is also shown. Subsequently, Morita et al. ${ }^{11)}$ investigated the effects of $\mathrm{Al}$, $\mathrm{Si}$, and $\mathrm{B}$ on the rate. It was shown that these elements de- crease the rate because of the weaker affinity with nitrogen than iron.

As described above and reviewed by Belton, ${ }^{12)}$ a large number of researches of nitrogen reaction rate with molten iron have been conducted. On the other hand, the reaction rate of nitrogen at the surface of solid iron has been investigated over 1960 to 1970's. Turkdogan and Grieveson ${ }^{13)}$ measured the nitrogen transfer rate for $\gamma-\mathrm{Fe}$ in $\mathrm{N}_{2}-\mathrm{H}_{2} \mathrm{O}-\mathrm{H}_{2}$ mixtures at $1273 \mathrm{~K}$ and showed the rate is proportional to the square root of the nitrogen partial pressure and is inversely proportional to the oxygen activity. Grabke ${ }^{14,15}$ ) measured the nitrogen dissociation rate at iron foils at 973 to $1273 \mathrm{~K}$ by the measurements of the electrical resistance of the iron foils in the flow apparatus in $\mathrm{N}_{2}-\mathrm{H}_{2}\left(-\mathrm{H}_{2} \mathrm{O}\right)$ mixtures and also showed the retarding effect of oxygen on the rate. These studies for solid iron are conducted at comparatively lower temperatures and it cannot be necessarily said that these results agree with each other, since the metal phase mass transfer may limit the rate in the measurements. Moreover, when the nitrogen activity decreases by the solutes, which have the stronger affinity with nitrogen, such as $\mathrm{Cr}$ and $\mathrm{Ti}$, it is considered important to understand the chemical reaction rates at the surface of solid iron alloys for the difficulty of decreasing the nitrogen contents. In the present study, the nitrogen dissociation rates at the surface of solid iron-M (M: Si, Al, Mn, Cr, and Ti) alloys have been measured by the isotope exchange technique, in which the measured values are not affected by the metal phase mass transfer in principle. The present results are compared with the results for the previous studies for solid iron at lower temperatures ${ }^{13-15)}$ and for molten iron based alloys ${ }^{8,11)}$ car- 
ried out by a similar method to the present work.

\section{Experimental}

An alumina crucible (26 mm O.D., $20 \mathrm{~mm}$ I.D.) containing high-purity electrolytic iron([mass ppm S] $=7$, [mass ppm $\mathrm{P}]=3$ ) weighing $100 \mathrm{~g}$ was inserted into a transparent quartz furnace tube and inductively heated up to $1873 \mathrm{~K}$ in an $\mathrm{Ar}-\mathrm{H}_{2}$ mixture and the iron sample was sufficiently deoxidized with $\mathrm{H}_{2}$. After it was held for $1 \mathrm{~h}$ at $1873 \mathrm{~K}$, the iron sample was cooled rapidly and was perpendicularly cut off at the height of $5 \mathrm{~mm}$. The surface of the iron sample was ground on a polishing board of No. 600. Using the iron sample preliminary prepared above, the measurements were conducted as follows. The sample was put in the alumina crucible, the size of which was equal to that used for the preparation and the clearance between the crucible and the sample was filled with alumina powder. The alumina crucible was inserted into the transparent quartz reaction chamber and inductively heated in a hydrogen to the experimental temperature, which was changed from 1473 to $1798 \mathrm{~K}$. The temperature of the sample was monitored by a dual wavelength infrared pyrometer, sighted onto the metal surface and adjusted manually to the desired temperature within an error of $\pm 3 \mathrm{~K}$. After reaching the experimental temperature, the ingoing gas was changed to an $\mathrm{Ar}-\mathrm{H}_{2}-\mathrm{N}_{2}$ mixture, and the measurements of the nitrogen dissociation rate on the metal sample were started. The nitrogen in the ingoing gas contains about $1 \mathrm{at} \%$ nitrogen isotope, ${ }^{30} \mathrm{~N}_{2}$. The total gas flow rate was $1000 \mathrm{~cm}^{3} / \mathrm{min}$ (s.t.p.) $\left(\bar{V}_{\mathrm{Ar}}=750\right.$, $\bar{V}_{\mathrm{H}_{2}}=200, \bar{V}_{\mathrm{N}_{2}}=50 \mathrm{~cm}^{3} / \mathrm{min}$ (s.t.p.)). The tip of the gas inlet tube (14.9 mm O.D., $10.8 \mathrm{~mm}$ I.D.) was located $5 \mathrm{~mm}$ above the metal surface and the gas mixture was blown onto the metal surface. A quadrupole mass spectrometer was used to measure the fraction of isotope nitrogen in the ingoing and outgoing gases, ${ }^{30} F_{\mathrm{i}}$ and ${ }^{30} F_{\mathrm{f}}$, through a quartz capillary tube $(0.375 \mathrm{~mm}$ O.D., $0.075 \mathrm{~mm}$ I.D.). The measurements were finished when the fraction of ${ }^{30} \mathrm{~N}_{2}$ for total nitrogen $\left({ }^{28} \mathrm{~N}_{2}+{ }^{29} \mathrm{~N}_{2}+{ }^{30} \mathrm{~N}_{2}\right)$ in the outgoing gas became unchanged and showed a constant value for $10 \mathrm{~min}$, which suggests the achievement of nitrogen equilibrium between gas and metal phases. The oxygen and nitrogen contents of the samples were analyzed after each experiment. Each oxygen content of the samples used in the present work is shown in Table 1. To prepare the alloying samples, the additive elements were initially mixed with the electrolytic iron in the alumina crucible before being inserted in the furnace.

As well as the case of the dissolution in the molten iron, when nitrogen dissolves into the solid iron, it is accompanied by the adsorption and dissociation of nitrogen at the metal surface. Accordingly, the same equation for the molten iron can be applied for the solid iron. The derivation of the equation for calculating a rate constant has been given elsewhere ${ }^{3,7,8,11)}$ and the summary is briefly described here. By considering a mass balance of ${ }^{30} \mathrm{~N}_{2}$, the following equation holds on the assumption that the fraction of ${ }^{30} \mathrm{~N}_{2}$ in the total absorbed nitrogen is equal to that in the ingoing nitrogen:

$$
\frac{P_{\mathrm{N}_{2}} \bar{V}}{R T}\left({ }^{30} F_{\mathrm{i}}-{ }^{30} F_{\mathrm{f}}\right)=A v\left({ }^{30} F_{\mathrm{i}}-{ }^{30} F_{\mathrm{eq}}\right)
$$

Table 1. The oxygen contents of the iron based alloy samples used in the present work.

\begin{tabular}{c|c}
\hline Sample & mass ppm O \\
\hline \hline $\mathrm{Fe}$ (Flow rate) & 11.9 \\
$\mathrm{Fe}$ (Temperature) & 10.3 \\
$\mathrm{Fe}-3$ mass $\% \mathrm{Ti}$ & 115 \\
$\mathrm{Fe}-10$ mass $\% \mathrm{Cr}$ & 23.2 \\
$\mathrm{Fe}-20$ mass $\% \mathrm{Cr}$ & 25.9 \\
$\mathrm{Fe}-3$ mass $\% \mathrm{Mn}$ & 10.2 \\
$\mathrm{Fe}-3$ mass $\% \mathrm{Al}$ & 11.8 \\
$\mathrm{Fe}-1$ mass $\% \mathrm{Si}$ & 12.8 \\
$\mathrm{Fe}-3$ mass $\% \mathrm{Si}$ & 14.7 \\
\hline
\end{tabular}

where $P_{\mathrm{N}_{2}}$ denotes the partial pressure of nitrogen (atm), $A$ the surface area of solid metal $\left(\mathrm{cm}^{2}\right), \bar{V}$ the volume flow rate $\left(\mathrm{cm}^{3} / \mathrm{s}\right), T$ the temperature of gas $(\mathrm{K}), R$ the gas constant $\left[=82.1\left(\mathrm{~cm}^{3} \cdot \mathrm{atm} / \mathrm{K} \cdot \mathrm{mol}\right)\right],{ }^{30} F_{\text {eq }}$ the equilibrium fraction of ${ }^{30} \mathrm{~N}_{2}$, and ${ }^{30} F_{\mathrm{i}}$ and ${ }^{30} F_{\mathrm{f}}$ the fractions of ${ }^{30} \mathrm{~N}_{2}$ in the ingoing and outgoing gases, respectively. Since nitrogen dissociates at the metal surface according to Eq. (2), the rate of nitrogen dissociation $v\left[\mathrm{~mol} /\left(\mathrm{cm}^{2} \cdot \mathrm{s}\right)\right]$, which is a first order with respect to the partial pressure of nitrogen, is expressed by Eq. (3),

$$
\mathrm{N}_{2}(\mathrm{~g})=2 \underline{\mathrm{N}}(\text { at the metal surface })
$$

$$
v=k P_{\mathrm{N}_{2}}
$$

where $k$ is the rate constant of nitrogen dissociation $\left[\mathrm{mol} /\left(\mathrm{cm}^{2} \cdot \mathrm{s} \cdot \mathrm{atm}\right)\right]$. Substitution of Eq. (3) into Eq. (1) gives the rate constant as follows:

$$
k=\frac{\bar{V}}{A R T} \cdot \frac{{ }^{30} F_{\mathrm{i}}-{ }^{30} F_{\mathrm{f}}}{{ }^{30} F_{\mathrm{i}}-{ }^{30} F_{\text {eq }}}
$$

\section{Results and Discussion}

\subsection{Nitrogen Dissociation Rate at the Surface of Pure Solid Iron}

Prior to the investigation of the effects of alloying elements, the rate of nitrogen dissociation at the surface of pure solid iron was measured at temperatures ranging from 1473 to $1773 \mathrm{~K}$, and the subsequent experimental conditions, such as the gas flow rate, were determined from those results. Figure 1 shows the dependence of the rate constant for high-purity iron on total flow rate, $\bar{V}_{\mathrm{N}_{2}+\mathrm{H}_{2}+\mathrm{Ar}}$, at $1773 \mathrm{~K}$, which is investigated by changing argon flow rate at constant hydrogen and nitrogen flow rates $\left(\bar{V}_{\mathrm{H}_{2}}=200, \bar{V}_{\mathrm{N}_{2}}=50\right.$ $\mathrm{cm}^{3} / \mathrm{min}$ (s.t.p.)). At lower flow rates, smaller rate constants are observed because of insufficient supply of the gases onto the metal surface. Accordingly, we need to measure at higher flow rates, which give a constant value for the rate constant. From Fig. 1, the total flow rate of $1000 \mathrm{~cm}^{3} / \mathrm{min}$ (s.t.p.) is shown to be necessary to eliminate the effect of gaseous mass transfer as much as possible. Based on these results, the subsequent measurements were carried out at a total flow rate of $1000 \mathrm{~cm}^{3} / \mathrm{min}$ (s.t.p.) $\left(\bar{V}_{\mathrm{H}_{2}}=200, \bar{V}_{\mathrm{N}_{2}}=50\right.$, $\bar{V}_{\mathrm{Ar}}=750 \mathrm{~cm}^{3} / \mathrm{min}$ (s.t.p.)). The dependence of the rate constant for pure solid iron on temperature is shown in Fig. 2 with the values for pure liquid iron ${ }^{3,8,11)}$ obtained by the same technique. The cause of the discrepancy among the values for pure liquid iron, in particular, between the data by Byrne et al. ${ }^{3)}$ and the others, ${ }^{8,11)}$ has not been clarified; it 


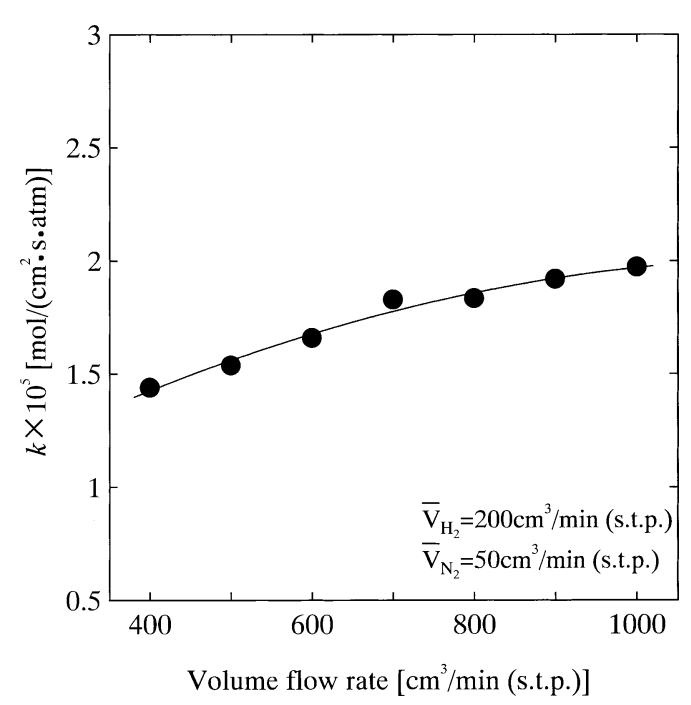

Fig. 1. Dependence of the rate constant for pure iron on total flow rate, $\bar{V}_{\mathrm{N}_{2}+\mathrm{H}_{2}+\mathrm{Ar}}$, at $1773 \mathrm{~K}$.

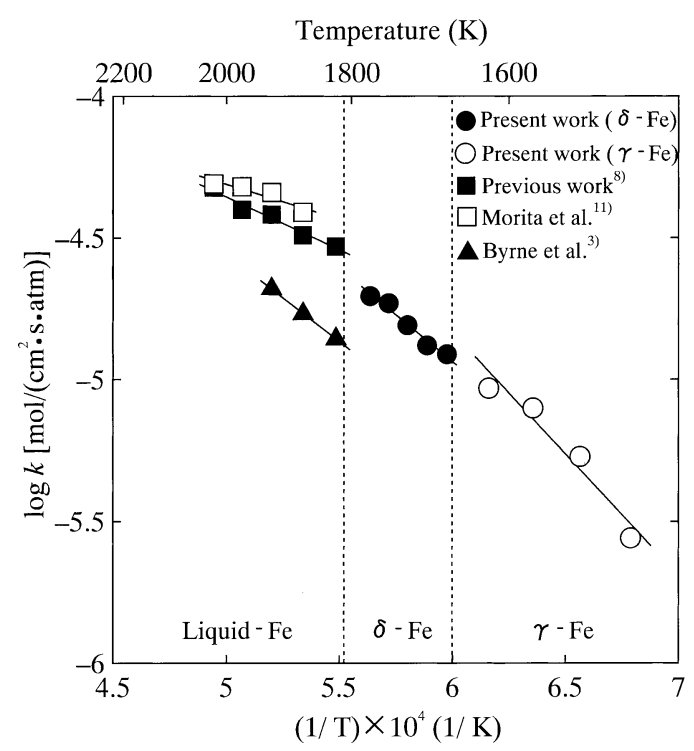

Fig. 2. Dependence of the rate constant of nitrogen dissociation at the surface of pure iron on temperature.

is considered that the difference may be explained by the oxygen content of metal, ${ }^{7,11}$ which is not mentioned in the article of Byrne et al. From this point of view, the present results should be compared with the values by Morita et $a l .{ }^{11)}$ or one of the present authors and others, ${ }^{8)}$ because the oxygen content of the present work, 10.3 mass ppm, is between that of the former, ${ }^{11)} 7$ to 8 mass ppm, and that of the latter, ${ }^{8)} 16$ mass ppm. It is found from Fig. 2 that the rate constants obtained by the present work are a little smaller than the values expected by extrapolating the values for the molten iron to lower temperatures and the logarithms of the rate constants show a linear relationship against the reciprocal of temperature. The linear relationships obtained by the regression analysis of the present results for $\delta$ - $\mathrm{Fe}$ and $\gamma$-Fe are described respectively as follows:

$$
\log k_{\delta \text { - } \mathrm{Fe}}=-\frac{6640}{T}-0.954 \quad(1673 \text { to } 1773 \mathrm{~K})
$$

Table 2. The activation energies for the reaction of nitrogen dissociation at the iron surfaces.

\begin{tabular}{|c|c|c|c|}
\hline & Phase & $\begin{array}{c}\text { Temperature } \\
(\mathrm{K})\end{array}$ & $\begin{array}{c}\text { Activation energy } \\
(\mathrm{kJ} / \mathrm{mol})\end{array}$ \\
\hline Present work ( $\delta$-Fe $)$ & \multirow{4}{*}{ Solid } & 1673 to 1773 & 127 \\
\hline Present work $(\gamma-\mathrm{Fe})$ & & 1473 to 1623 & 162 \\
\hline $\operatorname{Grabke}^{14)}(\gamma-\mathrm{Fe})$ & & 1185 to 1273 & 220 \\
\hline $\operatorname{Grabke}^{14)}(\alpha-\mathrm{Fe})$ & & 973 to 1185 & 235 \\
\hline Byrne et al. ${ }^{3)}$ & \multirow{5}{*}{ Liquid } & 1823 to 1923 & 121 \\
\hline Tsukihashi et al. $\left.{ }^{5}\right)\left(\mathrm{Fe}-\mathrm{C}_{\text {satod. }}\right)$ & & 1723 to 1873 & 113 \\
\hline Kobayashi et al. ${ }^{7)}$ & & 1823 to 1923 & 95 \\
\hline Previous work ${ }^{8)}$ & & 1823 to 2023 & 63 \\
\hline Morita et al. ${ }^{11)}$ & & 1873 to 2023 & 52 \\
\hline
\end{tabular}

$$
\log k_{\gamma-\mathrm{Fe}}=-\frac{8460}{T}+0.230 \quad(1473 \text { to } 1623 \mathrm{~K}) \ldots .
$$

The reaction rate of nitrogen dissociation at the surface of solid iron is largely affected by the amount of adsorbed solutes, which block the reaction sites at the surface. It is known that the adsorbed oxygen, sulfur, and nitrogen itself have large effects on the reaction rate of nitrogen dissociation at the surface of solid iron, in particular. The oxygen and sulfur contents of the iron used in the present work are 10.3 and 7 mass ppm, respectively, and the measurements were conducted at $P_{\mathrm{N}_{2}}=0.05$ (atm). From Eqs. (5) and (6), the apparent activation energies for the reaction of nitrogen dissociation at the surface of $\delta$-Fe and $\gamma$-Fe ([mass ppm $\mathrm{O}]=10.3$, [mass ppm S] $=7)$ at $P_{\mathrm{N}_{2}}=0.05(\mathrm{~atm})$ are calculated to be 127 and $162 \mathrm{~kJ} / \mathrm{mol}$, respectively. The activation energies for the molten iron reported by several investigators are shown in Table 2 with the present results. As described above, the amounts of the adsorbed solutes at the surface of the sample have a large effect on the calculated activation energies; it is necessary to know the difference of the solutes contents when those values are discussed. By comparing the apparent activation energies for $\delta$-Fe and $\gamma$ $\mathrm{Fe}$ derived in the present work with those for the molten iron, ${ }^{8,11)}$ the oxygen contents of which are almost the same as that of the present work, the values for the present work are found to be larger than those for the molten iron from Table 2. One of the reasons of their difference is considered to be caused by the temperature dependence of the amounts of the adsorbed solutes.

Grabke $^{14)}$ studied the nitrogen dissociation rate at iron foils in a $\mathrm{N}_{2}-\mathrm{H}_{2}$ mixture by the measurements of the electrical resistance of the iron foils. The results are shown by the dashed and dotted lines in Fig. 3 with the present results. The equations for $\alpha$-Fe and $\gamma$-Fe by Grabke are represented respectively as follows:

$$
\begin{gathered}
\log k_{\alpha}^{\prime}=-\frac{12280}{T}+1.643 \quad(973 \text { to } 1185 \mathrm{~K}) \ldots \\
\log k_{\gamma}^{\prime}=-\frac{11470}{T}+1.079 \quad(1185 \text { to } 1273 \mathrm{~K}) .
\end{gathered}
$$

From these equations, the apparent activation energies for $\alpha$-Fe and $\gamma$-Fe are calculated as 235 and $220 \mathrm{~kJ} / \mathrm{mol}$, respectively, which are larger than the values derived in the present study, as shown in Table 2. It can be found from 


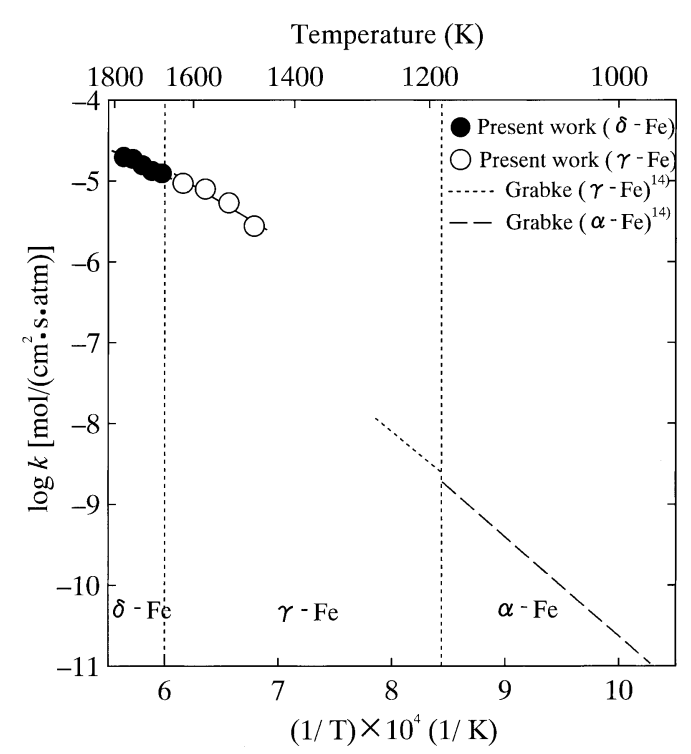

Fig. 3. Dependence of the rate constant of nitrogen dissociation at the surface of pure solid iron on temperature.

Fig. 3 that the present results are about two orders of magnitude higher than the data of Grabke, when the present results are extrapolated to lower temperatures. However, the existence of the adsorbed solutes taken into account, the difference may not be so large; the retarding effect of the adsorbed solutes, such as oxygen, on the rate appears more clearly at lower temperatures, which is confirmed by the measurements in $\mathrm{N}_{2}-\mathrm{H}_{2} \mathrm{O}-\mathrm{H}_{2}$ mixtures by Grabke. ${ }^{15)}$ The kinetics of nitrogenization and denitrogenization of $\gamma$-Fe is also studied under controlled oxygen partial pressures by Turkdogan and Grieveson ${ }^{13)}$ at $1273 \mathrm{~K}$ using iron strips. The measured rates are shown to be proportional to the square root of the nitrogen partial pressure, which suggests that the transfer of nitrogen atoms limits the reaction rate. For example, the rate constant, which is proportional to the first order of the nitrogen concentration in metal, is given to be $1.33 \times 10^{-6} \mathrm{~cm} / \mathrm{s}$ under the condition of $P_{\mathrm{H}_{2} \mathrm{O}} / P_{\mathrm{H}_{2}}=0.035$. Although the value cannot be converted to the rate constant directly comparable with the present results, the value is estimated much smaller than the present results. The discrepancy is considered to be probably caused by the oxygen contents and the difference of the rate limiting stage of the reaction.

Here, the effect of gaseous phase mass transfer on the rate constant obtained by the present work is estimated. According to the empirical equation by Kikuchi et al., ${ }^{16)}$ shown as Eq. (9), the Sh number is affected by the gas flow rate at the present condition $(\mathrm{Re}=6.87)$, and it can be calculated using the parameters shown subsequently.

$$
\mathrm{Sh}\left(=k_{\mathrm{g}} d / D\right)=(0.27 \pm 0.07)\left(r_{\mathrm{s}} / d\right)^{-1.5} \mathrm{Re}^{0.76} \mathrm{Sc}^{0.5}
$$

where $k_{\mathrm{g}}(\mathrm{cm} / \mathrm{s}), d(\mathrm{~cm}), D\left(\mathrm{~cm}^{2} / \mathrm{s}\right), r_{\mathrm{s}}(\mathrm{cm})$ denote the mass transfer coefficient of gas phase, the diameter of the gas blowing tube, the diffusion coefficient of the gas, and the radius of alumina crucible, respectively. In the present work, $d=1.08(\mathrm{~cm}), r_{\mathrm{s}}=1.0(\mathrm{~cm})$, and $D$ can be evaluated as $5.55 \mathrm{~cm}^{2} / \mathrm{s}$ from the Fuller's equation. ${ }^{17)}$ The Sh number is calculated as 0.100 and $k_{\mathrm{g}} / R T$ becomes $2.00 \times 10^{-4} \mathrm{~mol} /$ $\left(\mathrm{cm}^{2} \cdot \mathrm{s} \cdot \mathrm{atm}\right)$ at $1773 \mathrm{~K}$, while the rate constant for the pure
Table 3. The effect of the gaseous mass transfer on the rate constant of nitrogen dissociation in each experiment at $1773 \mathrm{~K}$.

\begin{tabular}{c|c|c|c}
\hline Sample & $\begin{array}{c}k\left[\mathrm{~mol} /\left(\mathrm{cm}^{2} \cdot \mathrm{s} \cdot \mathrm{atm}\right)\right] \\
\text { Measured }\end{array}$ & $\begin{array}{c}k^{\prime}\left[\mathrm{mol} /\left(\mathrm{cm}^{2} \cdot \mathrm{s} \cdot \mathrm{atm}\right)\right] \\
\text { Converted }\end{array}$ & $\begin{array}{c}\left(k^{\prime}-k\right) / k \\
(\%)\end{array}$ \\
\hline \hline $\mathrm{Fe}$ & $1.97 \times 10^{-5}$ & $2.18 \times 10^{-5}$ & 10.9 \\
$\mathrm{Fe}-3 \% \mathrm{Ti}$ & $2.40 \times 10^{-5}$ & $2.72 \times 10^{-5}$ & 13.6 \\
$\mathrm{Fe}-10 \% \mathrm{Cr}$ & $2.22 \times 10^{-5}$ & $2.49 \times 10^{-5}$ & 12.5 \\
$\mathrm{Fe}-20 \% \mathrm{Cr}$ & $2.48 \times 10^{-5}$ & $2.83 \times 10^{-5}$ & 14.1 \\
$\mathrm{Fe}-3 \% \mathrm{Mn}$ & $2.04 \times 10^{-5}$ & $2.27 \times 10^{-5}$ & 11.3 \\
$\mathrm{Fe}-3 \% \mathrm{Al}$ & $1.61 \times 10^{-5}$ & $1.75 \times 10^{-5}$ & 8.73 \\
$\mathrm{Fe}-1 \% \mathrm{Si}$ & $1.49 \times 10^{-5}$ & $1.61 \times 10^{-5}$ & 8.07 \\
$\mathrm{Fe}-3 \% \mathrm{Si}$ & $1.02 \times 10^{-5}$ & $1.07 \times 10^{-5}$ & 5.36 \\
\hline
\end{tabular}

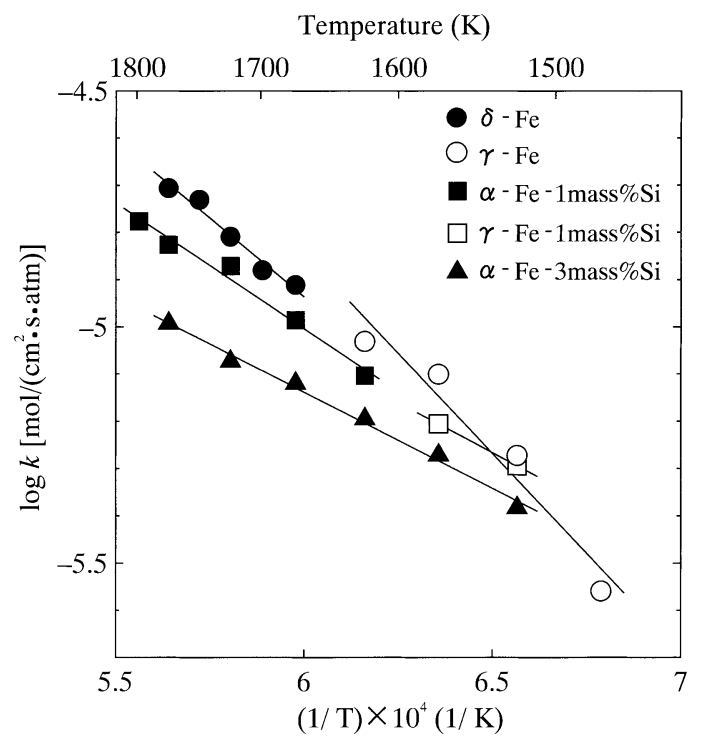

Fig 4. Dependence of the rate constant of nitrogen dissociation at the surface of $\mathrm{Fe}-\mathrm{Si}$ alloy on temperature.

solid iron was observed to be $1.97 \times 10^{-5} \mathrm{~mol} /\left(\mathrm{cm}^{2} \cdot \mathrm{s} \cdot \mathrm{atm}\right)$ at $1773 \mathrm{~K}$. The derived rate constant would be affected at most about $11 \%$ by the mass transfer in gas phase, and the chemical reaction rate constant would be converted as $2.18 \times 10^{-5} \mathrm{~mol} /\left(\mathrm{cm}^{2} \cdot \mathrm{s} \cdot \mathrm{atm}\right)$. Under the assumption of Eq. (9) applicable to all the present experiments, the effect of the gaseous mass transfer on the rate constants derived from the present experimental results was estimated in the same way. The results are shown in Table 3. The effect of the gaseous mass transfer on the measured rate constants can be estimated to be at most $15 \%$ from Table 3 .

\subsection{Effects of Alloying Elements}

The dependence of the rate constants for Fe-Si alloys on temperature is shown in Fig. 4 with the values for pure solid iron. The rate constants for $\mathrm{Fe}-\mathrm{Si}$ alloys are smaller than those for the pure solid iron at same temperature. It can be considered silicon in iron has the effect of decreasing the rate of nitrogen dissociation. The dependence of the rate constant on silicon concentration is shown in Fig. 5; the effect of silicon addition is appeared more clearly as the temperature increases. It is generally considered that the effect of atomic interaction becomes smaller as the temperature is raised and this seems to contradict the present results. The reason can not be explained at present and it is necessary to clarify the temperature dependence of the interaction for further discussion. The variation of the rate 


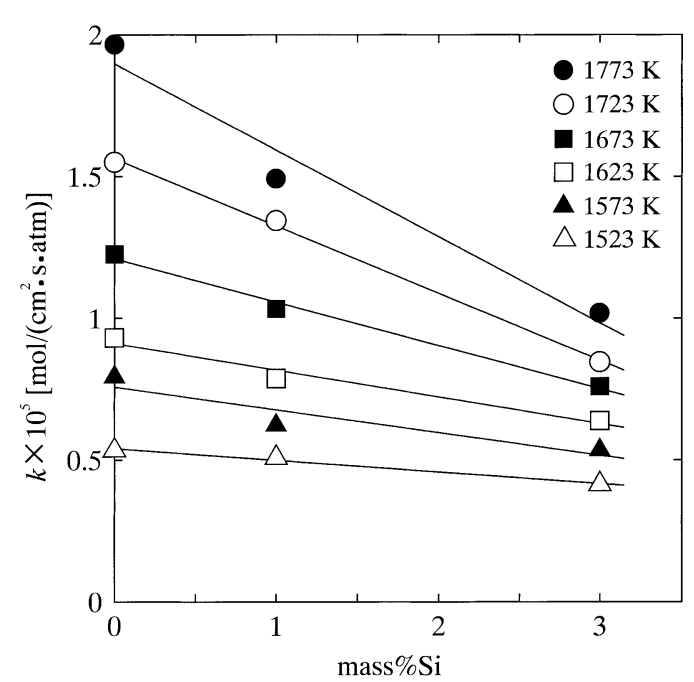

Fig. 5. Dependence of the rate constant of nitrogen dissociation on silicon content of iron.

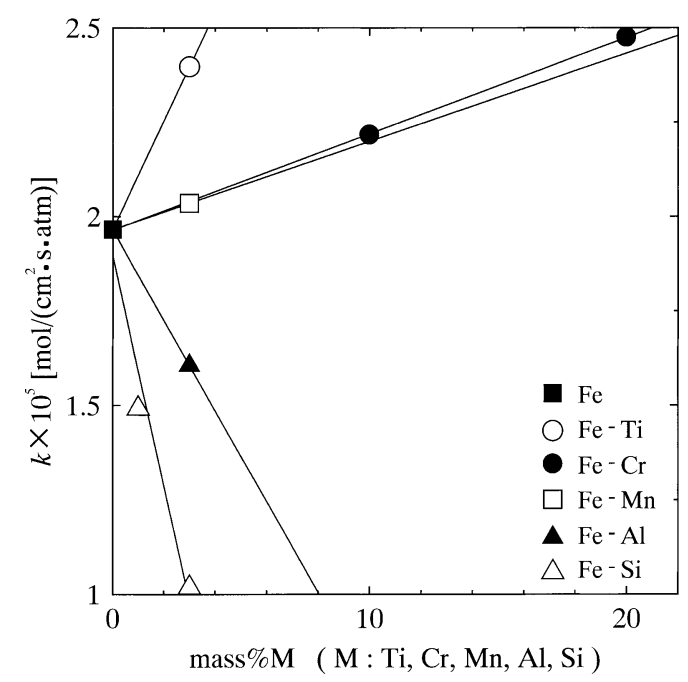

Fig. 6. Dependence of the rate constant of nitrogen dissociation on the additive element content of iron at $1773 \mathrm{~K}$.

constant with the contents of the alloying elements at $1773 \mathrm{~K}$ is shown in Fig. 6. From Fig. 6, the rate constant of nitrogen dissociation is found to be increased by the addition of Ti, Cr, and Mn. On the other hand, the addition of Si and $\mathrm{Al}$ causes the decrease of the rate of nitrogen dissociation. These tendencies for the effect of the alloying elements are equal to the results for the molten iron. ${ }^{8,11)}$ The effects of the alloying elements on the reaction rate at $1773 \mathrm{~K}$ are compared in Fig. 7, in which the effects are shown at the additive concentration range of less than 0.5 mass $\%$. The rate constant is demonstrated as a relative value to that for pure iron. It is found from Fig. 7 that, among the alloying elements investigated in the present work, the promoting effect of $\mathrm{Ti}$ is larger than that of $\mathrm{Cr}$ and $\mathrm{Mn}$, which have almost the same effect, and the retarding effect of $\mathrm{Si}$ is larger than that of $\mathrm{Al}$. The values for iron- 0.5 mass $\% \mathrm{M}(\mathrm{M}$ : $\mathrm{Si}, \mathrm{Al}, \mathrm{Mn}, \mathrm{Cr}$, and $\mathrm{Ti}$ ) alloys are compared with the previous work for the molten iron ${ }^{8,11)}$ in Table 4. From Table 4, in the addition of the elements with the promoting effect on the reaction rate ( $\mathrm{Ti}, \mathrm{Cr}$, and $\mathrm{Mn}$ ), the value for the liquid iron alloy is larger than that for the

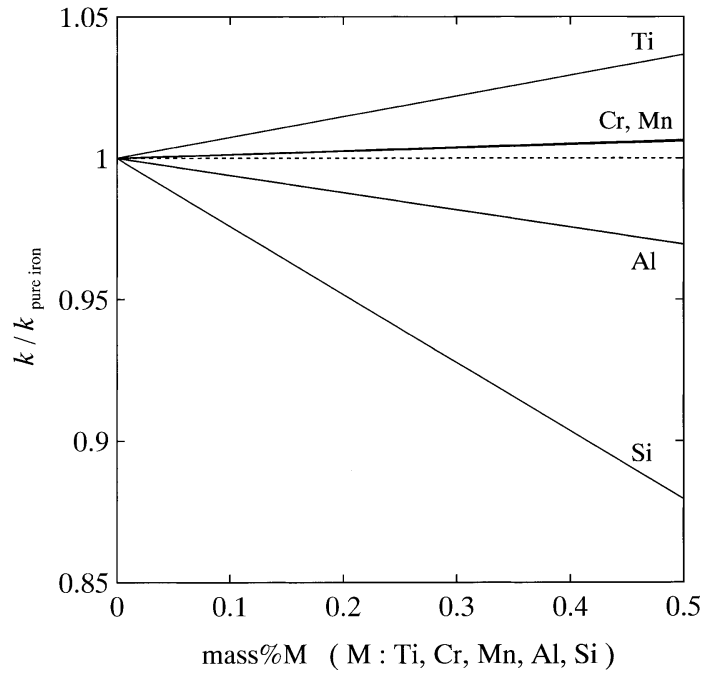

Fig. 7. Effect of the additive elements on the dissociation rate constant of nitrogen dissociation at the iron surface at $1773 \mathrm{~K}$.

Table 4. The relative values for the rate constant of $\mathrm{Fe}-0.5$ mass\% $\%(\mathrm{M}: \mathrm{Ti}, \mathrm{Cr}, \mathrm{Mn}, \mathrm{Al}$, and $\mathrm{Si}$ ) to that for pure iron, $k / k_{\text {pure iron }}$.

\begin{tabular}{|c|c|c|c|}
\hline & Present work & Previous work ${ }^{8}$ & Morita et al. ${ }^{11)}$ \\
\hline Phase & Solid & \multicolumn{2}{|c|}{ Liquid } \\
\hline Temperature & $1773 \mathrm{~K}$ & $1873 \mathrm{~K}$ & $1973 \mathrm{~K}$ \\
\hline $\mathrm{Ti}$ & 1.037 & 4.500 & - \\
\hline $\mathrm{Cr}$ & 1.006 & 1.008 & - \\
\hline $\mathrm{Mn}$ & 1.006 & - & - \\
\hline $\mathrm{Al}$ & 0.969 & - & 0.875 \\
\hline $\mathrm{Si}$ & 0.866 & - & 0.861 \\
\hline
\end{tabular}

solid. On the other hand, in the addition of the elements with the retarding effect on the reaction rate ( $\mathrm{Al}$ and $\mathrm{Si}$ ), the value for the liquid iron alloy is smaller. Therefore, it can be considered the effects of the alloying elements on the reaction rate of nitrogen dissociation are larger at the surface of the liquid iron in comparison with the solid iron. It is found that there is a large difference between the present result and the previous one for the molten iron ${ }^{8)}$ at the relative value for $\mathrm{Fe}-0.5 \mathrm{mass} \% \mathrm{Ti}$. Although the reason of this difference can not be explained explicitly, it may be caused by the difference of the amount of the added titanium; i.e., the added titanium was less than 0.1 mass $\%$ in the experiment for liquid iron $^{8)}$ and the extrapolated value is tabulated in Table 4, while the present experiment is carried out by adding titanium up to 3 mass $\%$. Moreover, the oxygen concentration of the sample may be the cause of this difference because it is analyzed 115 mass ppm for Fe-Ti alloy in the present work, while the sample for the liquid alloy was 15 to 20 mass ppm.

\section{Conclusions}

The nitrogen dissociation rates at the surface of solid iron-M (M: Si, Al, Mn, Cr, and Ti) alloys have been measured by an isotope exchange technique at temperatures ranging from 1473 to $1798 \mathrm{~K}$. The following results have been obtained.

(1) The nitrogen dissociation rate increases by the addition of titanium, chromium, and manganese. Among them, 
the promoting effect of titanium is the largest and chromium and manganese have almost the same effect.

(2) The nitrogen dissociation rate decreases by the addition of silicon and aluminum. The retarding effect of silicon is larger than that of aluminum.

(3) The effects of the alloying elements on the nitrogen dissociation rate at the surface of solid iron have the same tendency as those at the surface of liquid iron. The degree of the effects of increasing or decreasing the rate for the solid iron is smaller than that for the liquid iron.

(4) The apparent activation energies for the nitrogen dissociation at the surface of $\delta$-Fe and $\gamma$-Fe ([mass ppm $\mathrm{O}]=10.3$, [mass ppm S] $=7)$ at $P_{\mathrm{N}_{2}}=0.05(\mathrm{~atm})$ are calculated as 127 and $162 \mathrm{~kJ} / \mathrm{mol}$, respectively. The values are larger than that for the molten iron.

\section{Acknowledgments}

This work was supported by Iron and Steel Institute of Japan Research Promotion Grant. The authors thank Prof. K. Morita, The University of Tokyo, for his kind help and suggestions. We also thank Prof. K. Nogi and Dr. T. Matsumoto, Osaka University, for their kind help in analyzing the samples.

\section{REFERENCE}

1) R. D. Pehlke and J. F. Elliott: Trans. Metall. Soc. AIME, 227 (1963), 844.

2) R. J. Fruehan and L. J. Martonik: Metall. Trans. B, 11B (1980), 615.

3) M. Byrne and G. R. Belton: Metall. Trans. B, 14B (1983), 441.

4) P. C. Glaws and R. J. Fruehan: Metall. Trans. B, 16B (1985), 551.

5) F. Tsukihashi and R. J. Fruehan: Trans. Iron Steel Inst. Jpn., 27 (1987), 858.

6) S. Ban-ya, F. Ishii, Y. Iguchi and T. Nagasaka: Metall. Trans. B, 19B (1988), 233.

7) A. Kobayashi, F. Tsukihashi and N. Sano: ISIJ Int., 33 (1993), 1131.

8) H. Ono, K. Morita and N. Sano: Metall. Mater. Trans. B, 26 (1995), 991.

9) H. Ono, H. Fukagawa, K. Morita and N. Sano: Metall. Mater. Trans. $B, 27$ (1996), 846.

10) H. Ono, K. Iuchi, K. Morita and N. Sano: ISIJ Int., 36 (1996), 1245.

11) K. Morita, T. Hirosumi and N. Sano: Metall. Mater. Trans. B, 31B (2000), 899.

12) G. R. Belton: Metall. Trans. B, 24B (1993), 241.

13) E. T. Turkdogan and P. Grieveson: J. Electrochem. Soc., 114 (1967), 59.

14) H. J. Grabke: Ber. Bunsenges. Phys. Chem., 72 (1968), 541.

15) H. J. Grabke: Arch. Eisenhüettenwes., 44 (1973), 603.

16) A. Kikuchi, S. Taniguchi, T. Tadaki and S. Maeda: Theoretical and Applied Mechanics, Proc. Symp. International Union, Metal Society, London, (1982), 79.

17) E. N. Fuller, P. D. Schettler and J. C. Giddings: Ind. Eng. Chem., 58 (1966), 19. 